\section{Focal dermal hypoplasia in a male}

Leni George, Nisha Agrawal, Peter Hogan

Children's Hospital, Westmead, Sydney,

Australia

\section{Abstract}

Focal dermal hypoplasia (FDH) is a rare mesoectodermal dysplasia syndrome characterized by cutaneous, skeletal, dental, ocular and soft-tissue defects. An X-linked dominant mode of inheritance with lethality in male subjects has been proposed. Only around 30 cases of FDH have been reported in male subjects. Live born affected males are mosaic for mutations in PORCN gene. We present the mosaic pattern of FDH in a young boy.

\section{Case Report}

Focal dermal hypoplasia (FDH ) is a rare genodermatosis with multisystem involvement. It is an X-linked dominant disorder with high male lethality. ${ }^{1}$ Pathogenic mutations in the PORCN gene (locusXp11.23) is the molecular basis of FDH. ${ }^{2}$ Only around 30 cases have been reported in male subjects. Live-born affected males (10\% of affected individuals) are mosaic for mutations in PORCN. We present the mosaic pattern of FDH in a young boy.

A 11 year old boy, born of a non-consan-

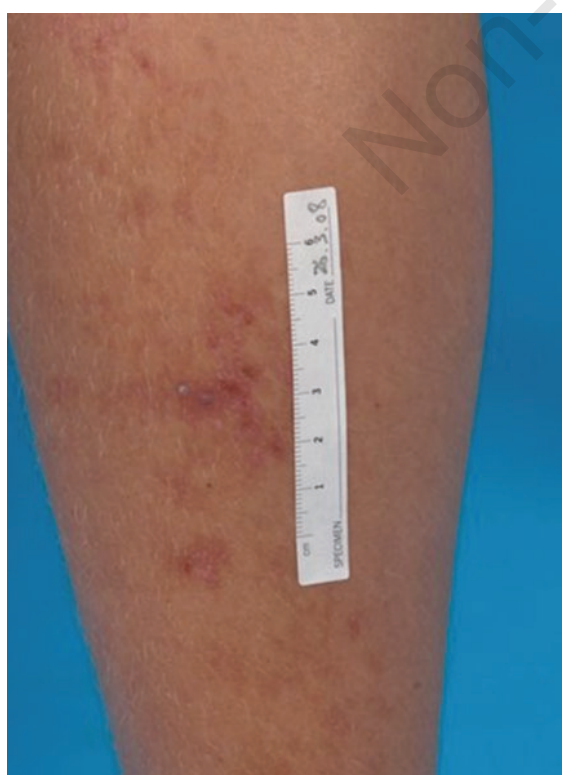

Figure 1. Linear cutaneous atrophy on the calf. guineous marriage, presented with a linear eruption that was first noticed around 18 months of age. It later progressed to involve most of the posterior aspect of his left calf (Figure 1). There were no systemic manifestations or any significant family history. Examination revealed erythema, hypopigmentation and subtle atrophy on an area of about 6 $\times 2 \mathrm{~cm}$ on the posterior aspect of his left leg. There were no other significant findings. Two skin biopsies were taken, from the lesional and the nonlesional skin to distinguish focal dermal hypoplasia from eccrine porokeratotic dermal duct nevus and aplasia cutis. The lesional skin showed mature adipose tissue in the papillary and subpapillary dermis with reduction in the total thickness of the dermis compared to the nonlesional skin ( $2.0 \mathrm{~mm}$ vs $2.4 \mathrm{~mm}$ ). This picture was consistent with FDH [Figures 2 and 3]. A dental evaluation revealed defective enamel and underdevelopment of the roots. Ophthalmologic and radiologic examinations were noncontributory. Genetic studies excluded Klinefelter's syndrome (XXY) phenotype. Based on the characteristic clinical and microscopic features, the patient was diagnosed to have a mosaic form of FDH. The inheritance pattern of FDH is X-linked dominant with a high lethality in males. Most male conceptuses with the mutant PORCN allele are

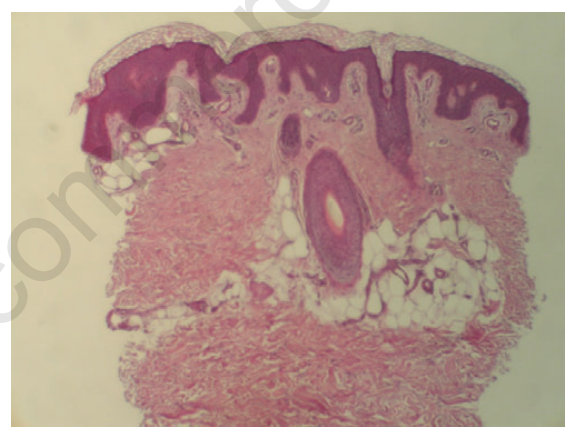

Figure 2. Low power view of lesion: replacement of papillary and upper reticular dermis by adipose tissue.

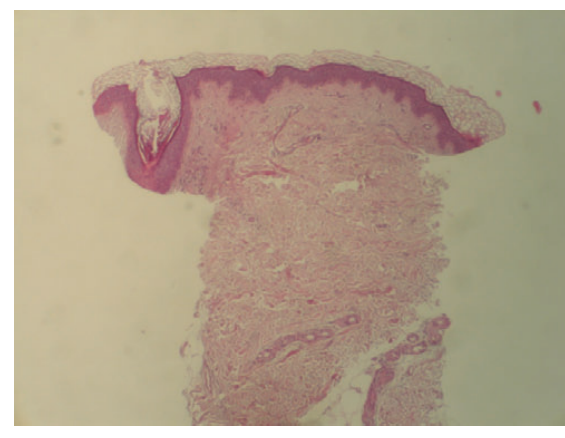

Figure 3. Low Power View of normal skin for comparison.
Correspondence: Peter Hogan, The Children's Hospital at Westmead,Westmead NSW 2145, Sydney, Australia.

Tel. +91.02.98450000 - Fax. +91.02.98453489.

E-mail: pandmhogan@optusnet.com.au.

Key words: focal dermal hypoplasia, mosaicism, postzygotic mutation.

Received for publication: 12 June 2011. Accepted for publication: 14 June 2011.

This work is licensed under a Creative Commons Attribution NonCommercial 3.0 License (CC BYNC 3.0).

(C) Copyright L. George et al., 2011

Licensee PAGEPress, Italy

Dermatology Reports 2011; 3:e7

doi:10.4081/dr.2011.e7

presumed to be spontaneously aborted. There are three possible explanations for focal dermal hypoplasia in males: i) 47XXY constitution and patients survive because of the extra $\mathrm{X}$ chromosome; ii) genomic X-chromosomal mosaicism resulting from early post zygotic mutation; iii) gametic half-chromatid mutation in which skin involvement is usually widespread, systematized and bilateral.

The most accepted explanation for male cases of FDH is attributed to postzygotic halfchromatid mutations, resulting in mosaicism, and the characteristic linear skin and bone defects. ${ }^{3}$ Mosaicism is a phenomenon in which only certain tissues are at risk of expressing the mutant X-chromosome as exemplified in our patient. Happle and Lenz suggested that the linear arrangement of the skin lesions may be the results of functional $\mathrm{X}$ chromosome mosaicism. ${ }^{4}$ Affected males are generally more mildly affected than females and this is probably due to the phenomenon of mosaicism. A recent review of the clinical and molecular features of individuals with FDH and PORCN gene mutations suggested that there was no clear genotype-phenotype correlation despite the variable clinical severity. ${ }^{5}$ Although molecular genetic testing could not be performed to confirm our diagnosis, clinically he had mosaic form of Goltz syndrome, which was confirmed on histopathology. As he had no major manifestations apart from dental anomalies, he was advised preventative dental care to reduce dental caries and follow up regularly to look for progression of the disease.

\section{References}

1. Goltz RW. Focal dermal hypoplasia syndrome: an update. Arch Dermatol 1992;128:1108-11. 
2. Wang X, Reid Sutton V, Omar PerazaLlanes $\mathrm{J}$, et al. Mutations in X-linked PORCN, a putative regulator of Wnt signaling, cause focal dermal hypoplasia. Nat Genet 2007;39:836-8.

3. Quain RD, Militello G, Junkins-Hopkins J, et al. Erythematous atrophic macules and papules following the lines of Blaschko. Arch Dermatol 2007;143:109-14.

4. Happle R, Lenz W. Striation of bones in focal dermal hypoplasia, a manifestation of functional mosaicism. Br J Dermatol
1977;96:133.

5. Clements SE, Mellerio JE, Holden ST, et al. PORCN gene mutations and the protean nature of focal dermal hypoplasia. $\mathrm{Br} \mathrm{J}$ Dermatol 2009;160:1103-9. 